\title{
INVESTIGACIONES
}

\section{Conceptualizaciones metafóricas sobre el rol del profesor en estudiantes de pedagogía*}

\author{
Pre-service Metaphorical Representations on Teacher's Role \\ Conceitualizações metafóricas sobre o papel do professor produzidas \\ por estudantes de pedagogia
}

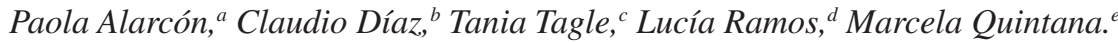 \\ ${ }^{a}$ Facultad de Humanidades y Arte, Universidad de Concepción. Fono: 56-41-2204794. \\ Correo electrónico: palarco@udec.cl

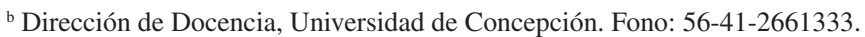 \\ Correo electrónico: claudiodiaz@udec.cl \\ ${ }^{c}$ Facultad de Educación, Universidad Católica de Temuco. Fono: 56-45-274456. \\ Correo electrónico: ttagle@uct.cl \\ ${ }^{d}$ Facultad de Ciencias Humanas, Universidad Arturo Prat. Fono: 56-57-384915. \\ Correo electrónico: lucia.ramos@unap.c1 \\ ${ }^{\text {e }}$ Facultad de Ciencias Humanas, Universidad Arturo Prat. Fono: 56-57-394441. \\ Correo electrónico: marcela.quintana@unap.cl
}

\begin{abstract}
RESUMEN
Los objetivos del estudio son identificar y analizar metáforas conceptuales producidas por estudiantes de pedagogía de la Universidad de Concepción (Chile) acerca de a) los profesores en Chile, b) los estudiantes de pedagogía. Los fundamentos teóricos de la investigación provienen de la metáfora conceptual y de la cognición docente. Se construyó un cuestionario para recoger las representaciones metafóricas de los sujetos. Las metáforas obtenidas se analizaron siguiendo la propuesta de Saban (2004), quien las clasifica en metáforas centradas en el profesor y metáforas centradas en el estudiante. Los resultados muestran que las metáforas acerca del profesor se ajustan en general a la clasificación de Saban y, además, se encontraron metáforas que revelan una valoración social negativa dada a los profesores; los sujetos conceptualizaron metafóricamente al estudiante de pedagogía principalmente como un ser vivo en desarrollo y como un héroe.
\end{abstract}

Palabras clave: cognición docente, metáfora conceptual, profesor, estudiante de pedagogía.

\section{ABSTRACT}

The aims of this study are to identify and analyze the conceptual metaphors produced by pre-service teachers from Universidad de Concepción (Chile) about a) teachers in Chile, and b) pre-service teachers. The theoretical

\footnotetext{
* $\quad$ Este estudio se inserta en los proyectos: "Investigación del conocimiento profesional, las creencias implícitas y el desempeño en aula de estudiantes de Pedagogía en Inglés como estrategia de generación de indicadores de monitoreo de su proceso formativo" (FONDECYT No 1120247); "Chilean Student-teachers' Metaphors about the Role of Teachers as Professionals" (Association for Researching and Applying Metaphor).
} 
framework of this research comes from two converging perspectives: teacher cognition and conceptual metaphor. A questionnaire was designed to collect subjects' metaphorical representations. The collected metaphors were analyzed based on Saban's (2004) proposal which distinguishes between teacher-centered and student-centered metaphors. The respondents' metaphors about teachers match with the properties Saban attributed to metaphors. Other metaphors reveal respondents' awareness of the negative loaded value assigned to teachers. Respondents conceptualize pre-service teachers metaphorically as a living being under development and as a hero.

Key words: teacher cognition, conceptual metaphor, teacher, pre-service teachers.

\section{RESUMO}

Objetiva-se identificar e analisar metáforas conceituais produzidas por estudantes de pedagogia da Universidad de Concepción (Chile) sobre: a) Os professores no Chile, b) Os estudantes de Pedagogia. Os fundamentos teóricos da investigação provém da metáfora conceitual e da cognição docente. Construiu-se um questionário para recolher as representações metafóricas dos sujeitos, as quais foram analisadas segundo a proposta de Saban (2004), que as classifica em metáforas centradas no professor e metáforas centradas no estudante. Resultados mostram que as metáforas sobre o professor se ajustam em geral à classificação de Saban e as demais revelam uma valoração social negativa dada aos professores; os sujeitos conceitualizaram metaforicamente o estudante de Pedagogia como um ser vivo em desenvolvimento e como um herói principalmente.

Palavras chave: cognição docente, metáfora conceitual, professor, estudante de pedagogia.

\section{INTRODUCCIÓN}

Durante los últimos años, la preocupación por los niveles de calidad, acceso y equidad de la educación chilena se ha extendido más allá del ámbito estrictamente educativo, ocupando un lugar central en el debate político y social. Los cuestionamientos a la preparación pedagógica, el nivel de ingresos económicos de las carreras de educación (ver Informe sobre las políticas nacionales de educación en Chile: OECD, 2004), las nuevas exigencias de habilitación profesional, entre otros aspectos, conforman un cuadro complejo $y$, a la vez, constituyen un desafío para los futuros profesores.

Dado que cada estudiante de pedagogía conceptualiza y recepciona sus estudios de formación pedagógica de manera diferente y única, la pregunta que guía esta investigación es ¿cuáles son las creencias que los estudiantes de pedagogía tienen sobre el rol del profesor y sobre su rol como estudiantes de una carrera de pedagogía?

En este estudio se integran dos perspectivas convergentes: la cognición docente y la metáfora conceptual. La metáfora constituye una herramienta robusta de investigación que permite develar el mundo cognitivo de los profesores en toda su complejidad y que recoge a su vez la esencia de lo que los profesores realmente creen sobre su propio rol y el de los estudiantes en el proceso formativo.

Los objetivos del estudio son: 1) identificar las metáforas producidas por un grupo de estudiantes de pedagogía de la Universidad de Concepción acerca de a) los profesores, b) los estudiantes de pedagogía; 2) analizar las implicaciones que provienen de estos conceptos metafóricos identificando los aspectos destacados por cada uno de ellos, así como las valoraciones positivas o negativas que portan.

\subsection{LA DIMENSIÓN COGNITIVA DEL DOCENTE}

La cognición docente comprende la dimensión cognitiva no observable de la enseñanza, es decir, lo que los profesores conocen, creen y piensan. Por ello, tiene un impacto considerable 
en la vida profesional de los docentes, quienes, desde esta perspectiva, son sujetos activos que toman decisiones utilizando redes complejas de conocimiento, pensamientos y creencias.

Las creencias están compuestas por conjuntos más o menos integrados y consistentes de ideas que se construyen a partir de las experiencias cotidianas. Pueden definirse de manera general como "entendimientos, premisas o proposiciones psicológicas sobre el mundo que se sienten como verdaderas" (Kane, Sanretto \& Heath, 2002: 178). En particular, las creencias docentes se entienden como "las formas personales en que un profesor entiende a los estudiantes, la naturaleza del aprendizaje, la sala de clases, el rol del profesor en el aula, los objetivos pedagógicos" (Borg, 2003: 100).

Diversos investigadores consideran que las creencias son uno de los constructos psicológicos más importantes para la formación docente (Díaz et al., 2010; Freeman, 2002; Pajares, 1992; Tillema, 1998), pues su comprensión permite contribuir a mejorar la formación profesional y las prácticas pedagógicas a través de la explicitación de los marcos de referencia mediante los cuales los docentes perciben y procesan la información, analizan, dan sentido y orientan su actuación pedagógica. Sin embargo, a pesar de su rol en el desempeño y en la formación de los profesores, las creencias no se prestan fácilmente para la investigación empírica, pero cuando se operacionalizan específicamente y se utiliza un diseño de investigación apropiado, los estudios de las creencias pueden ser muy relevantes. Por ello, en esta investigación se ha recurrido a la metáfora conceptual, pues debido a su función en la cognición (Lakoff \& Johnson, 1980), constituye una importante herramienta de análisis de las experiencias en el ámbito educacional y, particularmente, en el estudio de las creencias que los profesores -en ejercicio o en formación- tienen sobre sí mismos, y sobre sus experiencias y expectativas profesionales (Cameron, 2003; Kramsch, 2003; Low, 2008; Nikita \& Furuoka, 2008; Northcote, 2009; Oxford et al., 1998; Saban, 2006, 2004).

\subsection{METÁFORA CONCEPTUAL}

La metáfora conceptual es una de las áreas más prolíficas de investigación en Lingüística Cognitiva (Grady, 2007; Soriano, 2011). La Lingüística Cognitiva, enfoque según el cual el lenguaje es un instrumento para la organización del conocimiento, se basa en los siguientes principios teóricos: la pertinencia de las habilidades cognitivas en el estudio del lenguaje; la preeminencia de la semántica para el análisis lingüístico; la naturaleza experiencialista atribuida a los conceptos; las premisas de que el lenguaje es una capacidad integrada en la cognición general y de que su conocimiento por parte de los hablantes está basado en el uso (Geeraerts \& Cuyckens, 2007; Ibarretxe-Antuñano y Valenzuela, 2012).

Dentro de este enfoque, la metáfora se define como un conjunto sistemático de correspondencias entre dos dominios conceptuales, que surge de la proyección de elementos, propiedades y relaciones de un dominio más relacionado a la experiencia corporal y social, llamado dominio fuente, a un dominio más abstracto, llamado dominio meta (Grady, 2007; Kövecses, [2002] 2010; Lakoff \& Johnson, 1980; Soriano, 2011). El conjunto de correspondencias entre ambos dominios produce una lógica particular para cada metáfora mediante la cual razonamos. Por eso, en Lingüística Cognitiva se señala que el uso de las metáforas no es arbitrario, sino que al usarlas, las personas revelan las formas en que comprenden sus experiencias.

Las metáforas pueden servir como instrumento de análisis de las prácticas y experiencias humanas cotidianas (Oxford et al., 1998). En el ámbito del presente estudio, la literatura 
especializada muestra que los estudios de la metáfora se focalizan en las actitudes de los profesores en formación y en ejercicio hacia las prácticas del aula, la interacción profesorestudiante, y la evolución de las creencias acerca de la enseñanza y del aprendizaje (Dooley, 1998; Kasoutas \& Malamitsa, 2009; Knowles, 1994; Leavy, McSorley \& Boté, 2007; Mahlios \& Maxson, 1998). Entre los objetivos de este tipo de estudios se encuentra ayudar a los profesores a articular y construir representaciones sobre sí mismos y sobre sus experiencias profesionales; promover su conciencia sobre la práctica profesional, y mejorar su práctica en el aula (Cortazzi \& Jin, 1999; Kramsch, 2003; Nikitina \& Furuoka, 2008).

\subsubsection{Categorías conceptuales para el profesor}

Para guiar el análisis de los datos, se usó un conjunto de metáforas recogidas por Saban (2004), las cuales se generaron a partir de un análisis de los artículos de revistas sobre las imágenes metafóricas de la enseñanza y el aprendizaje a partir de diferentes bases de datos (por ejemplo: De Guerrero \& Villamil, 2002; Gillis \& Johnson, 2002; Inbar, 1996; Mahlios \& Maxson, 1998; Martínez, Sauleda \& Huber, 2001; Oxford et al., 1998).

Saban (2004) agrupó las metáforas en dos grandes perspectivas teóricas en educación caracterizadas como: (1) perspectiva centrada en el profesor y/u orientada a la instrucción, y (2) perspectiva centrada en el estudiante y/u orientada al aprendizaje. El marco organizativo para la agrupación de las metáforas se basa en las relaciones entre el profesor, el estudiante y los objetivos de la educación. Sobre la base de esta relación se levantaron diferentes categorías conceptuales que agrupan metáforas específicas (o ejemplares, en términos de Saban), sobre la base de aspectos clave o destacados. Como resultado de esta categorización, Saban (2004) establece que la perspectiva centrada en el profesor se centra más en la transmisión de conocimiento y la entrega de la instrucción; la perspectiva centrada en el estudiante, en cambio, se centra más en la facilitación del aprendizaje y en la participación activa de los estudiantes. En esta investigación, la clasificación de Saban sirve de marco referencial para el análisis, como se mostrará en las secciones siguientes.

\section{DISEÑO Y PROCEDIMIENTO}

\subsection{TÉCNICA DE RECOLECCIÓN DE DATOS}

Se siguió la línea de trabajos que recogen metáforas con la forma: " $\mathrm{X}$ es como $\mathrm{Y}$, porque...", donde $\mathrm{X}$ es el dominio meta que se busca conceptualizar, e $\mathrm{Y}$ es el dominio fuente que presta su estructura al dominio meta. Al igual que otros estudios, se pretende que los sujetos justifiquen la metáfora escogida. Dado que existen antecedentes sobre investigaciones previas con el mismo objeto de la presente investigación, en la que los sujetos no han logrado construir ni entregar metáforas (Wan, 2011), en el cuestionario se incluyó una breve definición. Luego, se presentaron 4 ejemplos de metáforas, fuera del ámbito de la educación. En seguida se ofreció una explicación en la que se señaló que para que se produzca la metáfora tienen que haber relaciones entre los elementos de dos ámbitos de la realidad, y se analizaron los ejemplos. A continuación de esta explicación se presentó el ítem en el que se solicitó que se completaran las oraciones: 
1. En la sociedad chilena, el profesor en cuanto profesional de la educación es visto como... porque...

2. Según su opinión, el estudiante de pedagogía es como... porque...

\subsection{VALIDACIÓN DE EXPERTOS}

Una vez construido el instrumento se le envió a 5 profesores universitarios del área de lingüística para que lo evaluaran. En base a sus observaciones, se tuvo que cambiar alguna terminología y simplificar la explicación.

\subsection{PARTICIPANTES}

El cuestionario se aplicó a 17 estudiantes de primer año de Pedagogía en Español y a 17 estudiantes de cuarto año de Pedagogía en Inglés.

\subsection{APLICACIÓN}

El cuestionario se aplicó en dos ocasiones durante el primer semestre de 2012 a los estudiantes de Pedagogía en Español y a los estudiantes de Pedagogía en Inglés en su sala de clases. En primer lugar, se les solicitó su consentimiento para participar en una investigación sobre representaciones metafóricas de los profesores y, en segundo lugar, se les entregó el cuestionario sin darles un límite de tiempo. Cada aplicación no duró más de 1 hora.

\subsection{PROCEDIMIENTO DE ANÁLISIS}

Se ocupó la técnica de análisis de metáforas conceptuales en una primera etapa. Posteriormente, estos resultados fueron sometidos a un análisis de contenido semántico de la investigación cualitativa. La identificación y el análisis de metáforas se desarrolló en las fases siguientes:

A. Identificación de metáforas conceptuales:

1. Se codificaron los cuestionarios.

2. Se identifican los enunciados donde los dominios fuentes configuraron los dominios meta. En esta etapa se consideró el contraste entre el significado básico (concreto) y el significado contextual, esto es, aquél que tiene en el dominio de la educación (dominio meta), de acuerdo con un procedimiento de análisis usado en investigaciones sobre metáfora conceptual (Pragglejaz Group, 2007).

3. Se agruparon los enunciados pertenecientes a la misma metáfora, es decir, aquellos con un dominio meta y dominio fuente común.

4. Se identificaron las propiedades más usadas de los dominios fuente en las metáforas, mediante lo cual se pretendió determinar los aspectos focalizados por cada metáfora.

B. Análisis de contenido semántico:

Luego de la identificación de las metáforas, se las sometió a un análisis de contenido semántico a fin de organizarlas en categorías, metáforas y aspectos destacados. Para esta tarea:

1. Se utilizó el software de análisis cualitativo ATLASTI.

2. A fin de asegurar la fiabilidad de los datos, se triangularon el análisis de los datos y las categorías emergentes. Cinco diferentes investigadores participaron en esta triangulación. 
3. Las metáforas y sus justificaciones fueron clasificadas de acuerdo con las categorías propuestas por Saban (2004).

4. Basados en el análisis de las justificaciones de las metáforas, hubo que reestructurar las categorías iniciales.

5. Para algunas metáforas, se propusieron nuevas categorías, a fin de dar cabida a metáforas relacionadas con la valoración social de los profesores. Este tipo de metáfora no estaba en el trabajo de Saban (2004).

\section{RESULTADOS Y DISCUSIÓN}

En esta sección se exponen los resultados obtenidos a partir del análisis de metáforas y del análisis de contenido semántico aplicado a las respuestas del cuestionario. Las metáforas específicas se organizaron en categorías, en las cuales se identificaron los aspectos destacados. Cuando hubo como respuesta más de una metáfora específica se puso la cantidad entre paréntesis, esto aparece en las tablas donde se presentan las metáforas ejemplares. Para cada categoría, la exposición se ilustrará con una o más respuestas.

\subsection{PREGUNTA 1: EN LA SOCIEDAD CHILENA, EL PROFESOR EN CUANTO PROFESIONAL DE LA EDUCACIÓN ES VISTO COMO... PORQUE...}

Una parte de las metáforas obtenidas se ajusta a la clasificación establecida por Saban (2004), ya que corresponden a metáforas centradas en el profesor/enseñanza y metáforas centradas en los estudiantes/aprendizaje. Dentro de esta clasificación mayor se encontraron también las mismas categorías conceptuales. No obstante, dado el valor de la experiencia y de la cultura en la conformación de las metáforas conceptuales no es extraño encontrar metáforas específicas diferentes a las encontradas por Saban (2004). Además, según las justificaciones entregadas por los sujetos a cada metáfora se establecieron sus aspectos destacados, algunos de los cuales coinciden con los establecidos por Saban (2004); sin embargo, se observan diferencias importantes en otros casos.

\subsubsection{Metáforas centradas en el profesor y/u orientadas a la instrucción}

Desde la perspectiva teórica centrada en el profesor, se encontraron las siguientes categorías conceptuales y sus metáforas ejemplares, como se expone en la Tabla 1.

Tabla 1. Metáforas centradas en el profesor y/u orientadas a la instrucción

\begin{tabular}{|l|ll|}
\hline \multicolumn{1}{|c|}{ Categoría conceptual para profesor } & \multicolumn{1}{c|}{ Metáforas ejemplares } \\
\hline El profesor como transmisor de conocimientos & - & Una luz \\
(y el alumno como receptor del conocimiento) & - & Un libro (2) \\
& - & Un cajero de banco \\
& - & Un espejo de la sociedad \\
& - & Una grabadora de audio \\
& - & Una ventana abierta hacia la mirada del \\
& conocimiento \\
\hline
\end{tabular}




\begin{tabular}{|c|c|}
\hline $\begin{array}{l}\text { El profesor como artesano } \\
\text { (y el estudiante como materia prima) }\end{array}$ & $\begin{array}{l}\text { - Una máquina productora de elementos } \\
\text { con compartidas características }\end{array}$ \\
\hline $\begin{array}{l}\text { El profesor como reparador } \\
\text { (y el estudiante como individuo defectuoso) }\end{array}$ & - $\quad$ Un instrumento ortopédico \\
\hline $\begin{array}{l}\text { El profesor como figura de autoridad superior } \\
\text { (y el estudiante como alguien obediente) }\end{array}$ & $\begin{array}{ll}\text { - } & \text { El pilar fundamental para el desarrollo } \\
\text { intelectual y cultural de los menores } \\
\text { - } & \text { Un presidente } \\
\text { - } & \text { Una columna que sostiene un edificio } \\
\text { - } & \text { Un padre }\end{array}$ \\
\hline
\end{tabular}

Fuente: elaboración propia.

\subsubsection{El profesor como transmisor de conocimientos}

La mayor cantidad de metáforas ejemplares pertenece a esta categoría. En relación con los aspectos clave establecidos por Saban (2004), las respuestas de los sujetos destacan sólo el que señala que el proceso de enseñanza-aprendizaje consiste en la transmisión y recepción de conocimiento, donde el profesor tiene el rol activo de entregarlo, y el estudiante el rol de destinatario pasivo. Por ejemplo:

1. El profesor es como una grabadora de audio, porque se cree que el profesor, cuando estudiante, memorizó todos los conceptos para luego reproducirlos de forma textual a sus estudiantes.

\subsubsection{El profesor como figura de autoridad superior}

En Saban (2004), esta categoría tiene como metáforas ejemplares el profesor como comandante, juez y guardián de prisión; las metáforas están centradas en el uso de la autoridad y el castigo; el ambiente en el aula implica un conjunto de relaciones de poder en la que el profesor tiene más autoridad que los estudiantes (es decir, decide qué y cómo enseñar). En cambio, en el presente estudio, las metáforas y sus respectivas justificaciones muestran, más bien, al profesor como una figura superior y con autoridad, la cual, aunque tiene el rol de corregir, obtiene también respeto mediante su conocimiento. Por ejemplo:

2. El profesor es como un padre, porque debe controlar que todo esté en orden, corregir las acciones que los verdaderos padres no corrigen.

3. El profesor es como una columna que sostiene un edificio, porque el profesor, de la misma manera que una columna, es visto como alguien firme, sólido y resoluto en sus acciones pedagógicas.

Para las otras dos categorías restantes se encontró sólo un caso para cada una, los que coinciden con los aspectos destacados establecidos por Saban (2004).

\subsubsection{El profesor como artesano}

En esta categoría, el docente se percibe como una persona altamente calificada cuya tarea principal es producir estudiantes como productos útiles para la sociedad, mientras que el estudiante sólo suministra la materia prima. 
4. El profesor es como una máquina productora de elementos con compartidas características, porque el profesor es visto como una máquina productora de elementos que se esperan respondan y se comporten todos de una misma manera esperada.

\subsubsection{El profesor como reparador}

En esta categoría de metáforas, según Saban (2004), el estudiante se percibe defectuoso desde el punto de vista de su intelecto y de su comportamiento y, por lo tanto, requiere reparación. El profesor es el que sabe lo que es correcto o no y su tarea principal es la de corregir los errores y deficiencias de los estudiantes, todo lo cual se observa en la respuesta siguiente:

5. El profesor es como un instrumento ortopédico, porque se pretende que corrija alteraciones o defectos que los individuos ya traen para que puedan ser funcionales.

\subsubsection{Metáforas centradas en el estudiante y/u orientadas al aprendizaje}

Desde la perspectiva teórica centrada en el estudiante, se encontraron las 4 categorías conceptuales y 7 metáforas ejemplares, como se muestra en la Tabla 2.

Tabla 2. Metáforas centradas en el estudiante y/u orientadas al aprendizaje

\begin{tabular}{|c|c|}
\hline Categoría conceptual para profesor & Metáforas ejemplares \\
\hline $\begin{array}{l}\text { El profesor como cuidador } \\
\text { (y el alumno como un organismo en desarrollo) }\end{array}$ & $\begin{array}{ll}\text { - } & \text { Una cuna } \\
\text { - } & \text { Una niñera (2) } \\
\text { - } & \text { Una mano amiga en quien confiar } \\
\text { - } & \text { Un padre o madre } \\
\text { - } & \text { Un padre sustituto }\end{array}$ \\
\hline $\begin{array}{l}\text { El profesor como animador } \\
\text { (y el estudiante como observador consciente) }\end{array}$ & - Un mago \\
\hline $\begin{array}{l}\text { El profesor como líder cooperativo } \\
\text { (y el estudiante como participante activo) }\end{array}$ & - $\quad$ Un director de orquesta \\
\hline
\end{tabular}

Fuente: elaboración propia.

\subsubsection{El profesor como cuidador}

Según Saban (2004), en esta categoría, el principal papel del profesor consiste en alimentar las capacidades potenciales de cada estudiante en un ambiente de aprendizaje de amor y cuidado, como se observa en: 
6. El profesor es como un padre sustituto, porque los alumnos pasan la mayor parte del tiempo en la escuela y el profesor es el encargado de brindarles apoyo, ayuda, conocimiento, facilitándoles su proceso de maduración y crecimiento.

Sin embargo, de acuerdo con las justificaciones ofrecidas por parte de los sujetos, en esta categoría se encontraron otras metáforas en las que no se destaca el rol del profesor en el proceso de aprendizaje de los estudiantes, sino más bien el rol del profesor como un cuidador:

7. El profesor es como una niñera, porque se espera que la niñera cuide al niño y lo entretenga, así como se espera que el profesor mantenga al alumno en la escuela. Además, si el alumno no estudia o no aprende es responsabilidad del profesor, así como si al niño se le irrita el trasero es responsabilidad de la niñera que no le puso especial atención.

8. El profesor es como una cuna, porque sólo sirve para cuidar niños.

En síntesis, hay dos perspectivas desde las cuales se concibe la categoría cuidador: una en la que se destaca el rol del profesor de apoyar y fomentar las capacidades de los estudiantes; mientras que desde la otra perspectiva se focaliza el rol de mantener satisfechas sus necesidades y tenerlos controlados mientras están bajo su responsabilidad.

\subsubsection{El profesor como animador}

De acuerdo con Saban (2004: 625), según esta categoría de metáforas, el profesor utiliza la actuación y la sorpresa como parte de la instrucción, en un intento de romper las barreras afectivas que impiden la comunicación y la participación por parte de los estudiantes. En este estudio, se encontró una respuesta en la que el profesor se muestra como una figura ligada al mundo de la entretención:

9. El profesor es como un mago, porque a veces se esperan muchas cosas de él (sin siquiera darle algo de ayuda). Porque si es bueno en lo que hace, puede lograr maravillas.

No obstante, como se puede observar en la justificación de la metáfora, no se destaca la dimensión lúdica, sino las expectativas sobre el trabajo del docente y la capacidad de éste para obtener buenos resultados, aunque no cuente con el apoyo necesario para ello.

\subsubsection{El profesor como líder cooperativo}

Coincidentemente con lo establecido por Saban (2004), en esta categoría, el profesor se encuentra en una posición de liderazgo y los estudiantes son participantes activos. En el marco de la representación metafórica del profesor como un director de orquesta, se implica que la clase es una orquesta sinfónica y los estudiantes serían los músicos, mientras que la interpretación musical sería la experiencia educativa diaria.

10. El profesor es como un director de orquesta, porque el director de orquesta y el profesor deben dirigir a un grupo hacia un buen funcionamiento y trabajo en equipo. Ambos deben ajustar detalles, que serán necesarios para que haya armonía entre todos los participantes. Ante los ojos de los demás, en él cae la responsabilidad del resultado final. 
En esta metáfora se destaca el trabajo en armonía, donde docente y alumnos realizan un trabajo conjunto, sin obviar que al primero le corresponde la responsabilidad del proceso.

\subsubsection{Metáforas centradas en la valoración social del profesor}

Se encontró un conjunto de metáforas cuyos aspectos destacados no se basan en un modelo de enseñanza-aprendizaje, sino que están centrados en la valoración social otorgada a los profesores en Chile. En la Tabla 3 se presentan las categorías conceptuales, las metáforas que allí se incluyen y los aspectos destacados en cada categoría.

Tabla 3. Metáforas centradas en la valoración social del profesor

\begin{tabular}{|c|c|c|}
\hline $\begin{array}{c}\text { Categoría conceptual para } \\
\text { profesor }\end{array}$ & Metáforas ejemplares & Aspectos destacados \\
\hline El profesor como un empleado & $\begin{array}{ll}\text { - } & \begin{array}{l}\text { El llenador de vacíos y } \\
\text { carencias que debe ser } \\
\text { crucificado }\end{array} \\
\text { - } & \text { Un mayordomo (2) } \\
\text { - } & \text { Un tramoya de circo pobre } \\
\text { - } & \text { Un producto multiuso de } \\
\text { calidad regular } \\
\text { - } & \text { Perro guardián encerrado } \\
\text { - } & \text { Un un pajio } \\
\end{array}$ & $\begin{array}{ll}\text { - } & \text { Trabajo asalariado } \\
\text { sujeto a la crítica } \\
\text { - } & \text { Falta de reconocimiento } \\
\text { social }\end{array}$ \\
\hline El profesor como un ser débil & $\begin{array}{ll}\text { - } & \text { Un niño indefenso } \\
\text { - } & \text { Un barco a la deriva } \\
\text { - } & \text { El pariente pobre }\end{array}$ & $\begin{array}{ll}\text { - } & \text { Fragilidad } \\
\text { - } & \text { Desprotección }\end{array}$ \\
\hline $\begin{array}{l}\text { El profesor como un ser } \\
\text { menospreciado }\end{array}$ & $\begin{array}{ll}\text { - } & \text { Un insecto } \\
\text { - } & \text { Una moneda de } \$ 10 \\
\text { - } & \text { Un tesoro sin valor }\end{array}$ & - Valoración negativa \\
\hline El profesor como devoto & - $\quad$ Un mártir & $\begin{array}{ll}\text { - } & \text { Entrega y servicio } \\
\text { - } & \text { Falta de reconocimiento } \\
& \text { social }\end{array}$ \\
\hline
\end{tabular}

Fuente: elaboración propia.

\subsubsection{El profesor como un empleado}

Se debe recordar que la pregunta del cuestionario hace referencia a la representación de los profesores existente en Chile, por tanto, se apela a la conciencia que tienen los sujetos acerca de cómo es concebida socialmente la profesión que eligieron. En esta categoría, los 
sujetos muestran estar conscientes de la representación del profesor como un empleado que desempeña diferentes funciones, no necesariamente pedagógicas, por las cuales recibe un trato indigno y una baja remuneración. Por ejemplo:

11. El profesor es como un mayordomo, porque debe servir a los propósitos del colegio de manera eficiente y sin reclamos, y estar siempre dispuesto a hacer las actividades que el colegio le solicite no importando que éstas no sean las de enseñanza.

\subsubsection{El profesor como un ser débil}

Relacionada con la categoría anterior, aquí se muestra una concepción del profesor como una figura que, en el contexto de las exigencias a las que se le somete y de la falta de valoración social que se le da, es considerado un profesional frágil e incomprendido.

12. El profesor es como un niño indefenso, porque todas las personas lo miran por debajo del hombro, pero no se dan cuenta que con el transcurso de los años, al igual que un niño, el profesor va a crecer.

\subsubsection{El profesor como un ser menospreciado}

Esta es una categoría que manifiesta con claridad la creencia que tienen los sujetos acerca de la valoración negativa dada al profesor. Según esta concepción, se implica que el profesor es menospreciado socialmente; que se elige la carrera de pedagogía porque tiene pocas exigencias, y que la profesión docente ocupa el lugar más bajo entre las profesiones, por ejemplo:

13. El profesor es como un insecto, porque es considerado el profesional más inferior y el que estudió esa carrera porque "no le alcanzó el puntaje" para otra carrera mejor remunerada.

\subsubsection{El profesor como mártir}

Esta metáfora se entiende en el contexto de las otras categorías. Si el docente es un profesional minusvalorado socialmente, al cual, además, se le somete a diferentes exigencias que, muchas veces, escapan al ámbito pedagógico, es razonable que exista una visión más comprensiva hacia él:

14. El profesor es como un mártir, porque se trata de una profesión que consume una energía superior, que es al mismo tiempo blanco de constantes críticas por las responsabilidades que delega la sociedad. Además, es de conocimiento general que los profesores no cuentan con tiempo suficiente para sus familias y/o actividades propias.

\subsection{PREGUNTA 2: SEGÚN SU OPINIÓN, EL ESTUDIANTE DE PEDAGOGÍA ES COMO... PORQUE...}

Se identificaron 6 categorías, las cuales se presentan con sus metáforas específicas y aspectos destacados, como se muestra en la Tabla 4. 
Tabla 4. Metáforas sobre el estudiante de pedagogía

\begin{tabular}{|c|c|c|}
\hline Categorías conceptuales & Metáforas ejemplares & Aspectos destacados \\
\hline $\begin{array}{l}\text { El estudiante de pedagogía } \\
\text { como un ser vivo en desarrollo }\end{array}$ & $\begin{array}{ll}\text { - } & \text { Una oruga } \\
\text { - } & \text { Una fruta sin madurar } \\
& \text { Un pequeño brote de } \\
\text { - } & \text { semilla } \\
& \text { Una luz que se quiere } \\
\text { convertir en estrella } \\
\text { - } & \text { Un pollito } \\
\text { - } & \text { Un libro abierto dispuesto } \\
\text { - } & \text { a ser escrito } \\
\text { Un árbol en proceso de } \\
\text { crecimiento } \\
\text { - } & \text { Una planta (2) } \\
- & \text { Un libro sin terminar } \\
- & \text { Un aver que aún no } \\
& \text { emprende el vuelo }\end{array}$ & $\begin{array}{ll}\text { - } & \text { Proceso de formación } \\
\text { profesional }\end{array}$ \\
\hline $\begin{array}{l}\text { El estudiante de pedagogía } \\
\text { como un héroe y un luchador }\end{array}$ & $\begin{array}{ll}- & \text { Un súper héroe } \\
\text { - } & \text { Don Quijote-soñador, } \\
& \text { luchador } \\
\text { - } & \text { Un valiente derribando } \\
& \text { obstáculos } \\
\text { - } & \text { Ulises en la Odisea } \\
\text { - } & \text { Un soñador } \\
\text { - } & \text { El Principito, de Antoine } \\
& \text { de Saint-Exupery } \\
- & \text { Un superhéroe } \\
- & \text { Un romántico idealista } \\
- & \text { Un gladiador entrando en } \\
& \text { la arena de juego } \\
\text { - } & \text { Un salmón } \\
\end{array}$ & $\begin{array}{ll}\text { - } & \text { Superación de obstáculos } \\
\text { en busca de una meta } \\
\text { - } & \text { Enfrentamiento de } \\
\text { adversidades }\end{array}$ \\
\hline $\begin{array}{l}\text { El estudiante de pedagogía } \\
\text { como un ser menospreciado }\end{array}$ & $\begin{array}{ll}\text { - } & \text { Un marginado } \\
\text { - } & \text { El que no podía para más } \\
\text { - } & \text { La/el niña/o fea/o del baile } \\
\text { - } & \text { Lo que lanzó la ola } \\
\text { - } & \text { Un insulto }\end{array}$ & - $\quad$ Valoración negativa \\
\hline $\begin{array}{l}\text { El estudiante de pedagogía } \\
\text { como un transmisor de } \\
\text { conocimiento }\end{array}$ & $\begin{array}{ll}\text { - } & \text { Una grabadora } \\
\text { - } & \text { Una esponja } \\
\text { - } & \text { Un bolso } \\
\end{array}$ & $\begin{array}{l}\text { - } \quad \text { Entrega de conocimientos } \\
\text { a los estudiantes }\end{array}$ \\
\hline $\begin{array}{l}\text { El estudiante de pedagogía } \\
\text { como un entretenedor } \\
\text { remunerado }\end{array}$ & $\begin{array}{ll}- & \text { Un actor } \\
- & \text { Un actor de teatro }\end{array}$ & $\begin{array}{ll}\text { - } & \text { Precariedad económica } \\
\text { - } & \text { Transmisión de } \\
\text { conocimiento }\end{array}$ \\
\hline $\begin{array}{l}\text { El estudiante de pedagogía } \\
\text { como un empleado }\end{array}$ & - $\quad$ Un maestro chasquilla & - $\quad$ Trabajo multifuncional \\
\hline
\end{tabular}

Fuente: elaboración propia. 


\subsubsection{El estudiante de pedagogía como un ser vivo en desarrollo}

Estas metáforas se centran en el desarrollo de los estudiantes de pedagogía en cuanto a su formación profesional. Por ejemplo:

15. El estudiante de pedagogía es como una oruga, porque poco a poco debe romper el capullo hasta sobrevolar los diversos paisajes del conocimiento.

16. El estudiante de pedagogía es como una fruta sin madurar, porque de a poco se van adquiriendo las herramientas necesarias para llegar a ser un buen profesor, al igual que una fruta que está en proceso de madurar.

\subsubsection{El estudiante de pedagogía como un héroe y un luchador}

Los sujetos valoran positivamente el estudiar pedagogía. Si observamos que los sujetos tienen conciencia de la carga negativa que tiene ser profesor en la sociedad chilena, es comprensible que el decidir estudiar esta carrera se configure en términos de heroísmo, por ejemplo:

17. El estudiante de pedagogía es como un gladiador entrando en la arena de juego, porque sabe a lo que va, pero de igual forma afronta los problemas del modo en que pueda, sin miedo.

18. El estudiante de pedagogía es como Ulises en la Odisea, porque está lleno de obstáculos y tentaciones, pero dispuesto a todo para llegar hasta el final.

\subsubsection{El estudiante de pedagogía como un ser menospreciado}

Esta categoría es coherente con la categoría El profesor como un ser menospreciado (ver 3.1.3.3), ya que si la profesión docente es tan mal evaluada socialmente, quien elige estudiar la carrera de pedagogía lo hace porque no tiene otra opción.

19. El estudiante de pedagogía es como la/el niñalo fealo del baile, porque en la universidad o en tu entorno familiar cuando te preguntan qué estudias y tú respondes pedagogía, ellos quedan sorprendidos y a veces decepcionados con la respuesta. Lo consideran como la última opción en la universidad.

20. El estudiante de pedagogía es como lo que lanzó la ola, porque está visto que el estudiante de pedagogía es lo que lanzó la ola luego de dar la PSU, gente [a la] que no alcanzó el puntaje suficiente para una carrera "buena", es sí [sic] como una "Ingeniería", "Medicina".

Las respuestas muestran que los sujetos son conscientes de la percepción negativa de su entorno con respecto a la carrera que escogieron.

\subsubsection{El estudiante de pedagogía como un transmisor de conocimiento}

Estas metáforas responden a una concepción centrada en la transmisión de conocimiento, donde al profesor le corresponde el rol de transmitirlo y al estudiante el rol pasivo de recibirlo (ver 3.1.1.1). Por ejemplo:

21. El estudiante de pedagogía es como una grabadora, porque debe aprender a grabarse, por así decirlo, todo lo que aquí se nos enseña, con el fin de algún día poder aplicarlo y enseñarlo a otros. 
22. El estudiante de pedagogía es como una esponja, porque absorbe conocimientos, al igual que una esponja absorbe agua para luego entregarla, imitando la acción de una esponja cuando bota el agua.

Esta categoría abre la interrogante de cuánto de esta concepción del proceso de enseñanza-aprendizaje corresponde a la experiencia de los sujetos en relación con su formación universitaria, es decir, si se basa en un modelo de enseñanza universitario, el cual ellos, eventualmente, aplicarán en su ejercicio profesional.

\subsubsection{El estudiante de pedagogía como un entretenedor remunerado}

La imagen del profesor como un personaje ligado al mundo del espectáculo y la diversión destaca el rol de satisfacer la curiosidad de los alumnos mediante la entretención (Saban, 2004: 625). No obstante, en las respuestas siguientes, se observa que la imagen de actor destaca otros aspectos, tales como la vocación a pesar de la precariedad económica de la profesión (23) o la transmisión de conocimientos y las diferentes funciones que deben cumplir los profesores en su desempeño laboral (24).

23. El estudiante de pedagogía es como un actor de teatro, porque sabe que en su campo no se hará rico ni vivirá con lujos, pero prefiere eso a hacer algo que no ama por el resto de su vida.

24. El estudiante de pedagogía es como un actor, porque debe aprender diversos contenidos para después enseñarlos en la práctica, así como el actor aprende guiones para interpretar muchos roles.

\subsubsection{El estudiante de pedagogía como un empleado}

Con la expresión "maestro chasquilla" se designa en el español de Chile a un trabajador que desempeña diferentes labores (gasfitería, electricidad, etc.), sin tener una especialidad definida ni contar con una formación profesional necesariamente; esta representación se observa en la respuesta (25), en la que se destaca la multifuncionalidad del trabajo docente, aunque no siempre se cuente con la preparación o capacidad suficiente para responder a todas las tareas:

25. El estudiante de pedagogía es como un maestro chasquilla, porque debe aprender múltiples actividades, debe tener conocimiento de muchas áreas, estar dispuesto a arreglar diversos problemas que acontecen, sin tener siempre clara la solución y debe improvisar para salir adelante cuando hay dificultades.

\section{CONCLUSIONES}

Al aplicar la propuesta de Saban (2004), se observa que efectivamente es posible determinar metáforas centradas en el profesor/enseñanza y metáforas centradas en los estudiantes/ aprendizaje. Se debe señalar, sin embargo, que existen diferencias en cuanto a las metáforas específicas mediante las cuales se representa al profesor o al estudiante de pedagogía. 
En las respuestas a la pregunta 1, resalta la concepción del proceso de enseñanzaaprendizaje centrada en el profesor y basada en la transferencia de conocimiento. Es válida entonces la pregunta sobre cómo la experiencia de los sujetos en cuanto estudiantes incide en sus concepciones metafóricas. Además, se observaron diferencias en los aspectos destacados por las diferentes categorías. En la propuesta de Saban (2004) estos rasgos están ligados al proceso educativo, en cambio, en esta investigación, algunos aspectos se orientan a la dimensión laboral de los profesores. Esto se refleja también en la categoría de valoración social, en la que los sujetos manifiestan sus creencias con respecto a la forma en que los profesores son evaluados socialmente, categoría que no aparece en Saban (2004).

Estas representaciones del profesor en Chile son coherentes con las respuestas a la pregunta 2. El estudio muestra que los sujetos están conscientes de la valoración negativa que se le da a la profesión docente y ello explica las metáforas que conceptualizan al estudiante de pedagogía como un héroe que vence obstáculos, pues por vocación elige una profesión difícil, pero también al elegir esta carrera es menospreciado por su entorno; con respecto al proceso de enseñanza-aprendizaje, nuevamente las metáforas predominantes son las centradas en la transmisión de conocimiento.

Cada metáfora conlleva un conjunto de rasgos que focaliza ciertas propiedades del dominio meta (Kövecses, 2010). Cuando los sujetos expresan su justificación o explicación de la metáfora, vemos que conceptos como EL PROFESOR ES COMO UN PADRE tienen valoraciones diferentes. Desde una perspectiva, se configura al docente como alguien preocupado por dar apoyo a los estudiantes, pero otro sujeto, en su justificación de la metáfora, lo concibe como una figura de autoridad, que corrige a los alumnos. Algo similar ocurre con EL PROFESOR ES COMO UN ACTOR. Saban (2004) alude a su carácter de figura del espectáculo y de la entretención; en cambio, en este estudio, un sujeto escoge como rasgo metafórico su precariedad laboral. En otras palabras, las metáforas muestran también las diferentes dimensiones del dominio fuente, es decir, de cómo se conceptualiza al actor en Chile, por ejemplo.

Según el enfoque de la metáfora usado en este estudio, los conceptos tienen una base en la experiencia corporal, social y cultural. Surgen otras pregunta entonces, como ¿cuáles son los conceptos metafóricos para profesor en otras culturas?; ¿cuán diferentes son estos conceptos en sociedades con mejores condiciones laborales para los profesores?; ¿cuánto influyen las percepciones negativas en el sentido de autoeficacia docente (Tschannen-Moran \& Woolfolk, 2001)?; ¿mediante qué estrategias se puede intervenir en las concepciones metafóricas?

En cuanto a la metodología, el cuestionario resultó efectivo, dado que hubo sólo 2 respuestas de 68 en que no se produjeron metáforas. Al respecto, se estimó que el proceso de análisis requiere de una explicitación detallada de los criterios mediante los cuales determinar qué respuestas se consideran en el estudio. Así, a las fases de análisis definidas inicialmente en la investigación, se tuvo que agregar otras, ya contempladas por Saban (2004), Kocbeker y Saban (2007), a saber, agregar una etapa de clarificación o eliminación de metáforas, en la que se establecen los criterios mediante los cuales se eliminan respuestas. Es el caso de la respuesta a la pregunta 1: "el profesor es como un hombre sabio", que corresponde a lo que Saban (2006) denomina simple descripción, pues no se involucran dos dominios conceptuales, sino que sólo se define literalmente un concepto; el otro caso que se encontró es el que Saban (2006) llama metáfora híbrida o difusa, en el que no se establece con claridad el dominio fuente involucrado; esto ocurrió con la respuesta 
"el profesor es como alguien que abre oportunidades y horizontes", donde no hay una imagen definida para representar metafóricamente al profesor y, además, se mezcla una idea concreta (abrir) con conceptos abstractos (oportunidades y horizontes).

La metáfora es parte central en la cognición y, por ello, su análisis puede contribuir a la formación inicial de profesores, puesto que se presenta como una técnica para la explicitación de creencias respecto de las variables y participantes fundamentales del proceso de enseñanza-aprendizaje; además, las metáforas pueden ayudar a los sujetos a verbalizar y tomar conciencia sobre su identidad profesional. Por lo mismo, la realización de este tipo de estudios es pertinente cuando se pretende desarrollar, de ser necesario, estrategias que permitan guiar a los estudiantes de pedagogía en el proceso de transformación de estas creencias tácitas en creencias explícitas, teniendo en consideración el efecto que pueden tener en su representación de sí mismos y en su desempeño una vez que se insertan en un ambiente profesional.

Estos resultados corresponden a una fase inicial del estudio. Las siguientes etapas son analizarlos en relación con otras variables que se incluyeron en el cuestionario: sexo, edad, etnia, proveniencia escolar (escuela pública, privada); aplicar el instrumento a un mayor número de estudiantes de pedagogía e investigar si existen diferencias según el nivel en que se encuentran y según la especialidad que cursan; aplicar otros instrumentos: un cuestionario con escala LIKERT creado a partir de los resultados de la presente investigación y, además, usar la técnica de grupo focal para recoger metáforas, de modo de someter estos resultados a un análisis estadístico descriptivo en su dimensión cuantitativa.

\section{REFERENCIAS BIBLIOGRÁFICAS}

Borg, S. (2003). Teacher Cognition in Language Teaching: A Review of Research on What Language Teachers Think, Know, Believe, and Do. The International Abstracting Journal for Language Teachers and Applied Linguists, vol. 36, n. 2, 81-109.

Cameron, L. (2003). Metaphor in Educational Discourse. London: Continuum.

Cortazzi, M. \& Jin, L. (1999). Bridges to Learning: Metaphors of Teaching, Learning and Language. In L. Cameron \& G. Low (Eds.), Researching and Applying Metaphor (pp. 149-176). Cambridge: Cambridge University Press.

De Guerrero, M. C. M. \& Villamil, O. S. (2001). Metaphor Analysis in Second/Foreign Language Instruction: A Sociocultural Perspective. Annual Meeting of the American Association of Applied Linguistics (pp. 24-27). St. Louis, MO.

Díaz, C., Martínez, P., Roa, I. y Sanhueza, M. G. (2010). Una fotografía de las cogniciones de un grupo de docentes de inglés de secundaria acerca de la enseñanza y aprendizaje del idioma en establecimientos educacionales públicos de Chile. Folios, n. 31, 69-80.

Dooley, C. (1998). Teaching as a Two-way Street: Discontinuities among Metaphors, Images, and Classroom Realities. Journal of Teacher Education, vol. 49, n. 2, 97-107.

Freeman, D. (2002). The Hidden Side of the Work: Teacher Knowledge and Learning to Teach. A Perspective from North American Educational Research on Teacher Education in English Language Teaching. Language Teaching. The International Abstracting Journal for Language Teachers and Applied Linguists, vol. 35, n. 1, 1-13.

Geeraerts, D. \& Cuyckens, H. (2007). Introducing Cognitive Linguistics. In D. Geeraerts \& H. Cuyckens (Eds.), The Oxford Handbook of Cognitive Linguistics (pp. 3-21). Oxford: Oxford University Press.

Gillis, C. \& Johnson, C. (2002). Metaphor as Renewal: Re-imagining our Professional Selves. 
English Journal, vol. 91, n. 6, 37-43.

Grady, J. E. (2007). Metaphor. In D. Geeraerts \& H. Cuyckens (Eds.), The Oxford Handbook of Cognitive Linguistics (pp. 188-213). Oxford: Oxford University Press.

Ibarretxe-Antuñano, I. y Valenzuela, J. (2012). Lingüística cognitiva: Origen, principios y tendencias. En I. Ibarretxe-Antuñano y J. Valenzuela (Coords.), Lingüística Cognitiva (pp. 13-38). Barcelona: Anthropos.

Inbar, D. (1996). The Free Educational Prison: Metaphors and Images. Educational Research, vol. 38, n. 1, 77-92.

Kane, R., Sanretto, S. \& Heath, C. (2002). Telling Half the Story: A Critical Review of Research on the Teaching Beliefs and Practices of University Academics. Review of Educational Research, vol. 72, n. 2, 177-228.

Kasoutas, M. \& Malamitsa, K. (2009). Exploring Greek Teachers' Beliefs Using Metaphors. Australian Journal of Teacher Education, vol. 34, n. 2, 64-83.

Kövecses, Z. ([2002] 2010). Metaphor: A Practical Introduction ( $2^{\text {nd }}$ Ed.). Oxford \& New York: Oxford University Press.

Knowles, J. G. (1994). Metaphors as Windows on a Personal History: A Beginning Teacher's Experience. Teacher Education Quarterly, vol. 27, n. 1, 37-66.

Kramsch, C. (2003). Metaphor and the Subjective Construction of Beliefs. In P. Kalaja \& A. M. F. Barcelos (Eds.), Beliefs about SLA: New Research Approaches (pp. 109-128). Dordrecht: Kluwer Academic Publishers.

Lakoff, G. \& Johnson, M. (1980). Metaphors We Live By. Chicago: University of Chicago Press.

Leavy, A. M., McSorley, F. A. \& Boté, L. A. (2007). An Examination of What Metaphor Construction Reveals about the Evolution of Pre-service Teachers' Beliefs about Teaching and Learning. Teaching and Teacher Education, vol. 23, n. 7, 1217-1233.

Low, G. (2008). Metaphor and Education. In R. Gibbs (Ed.), The Cambridge Handbook of Metaphor and Thought (pp. 212-231). Cambridge: Cambridge University Press.

Mahlios, M. \& Maxson, M. (1998). Metaphors as Structures for Elementary and Secondary Preservice Teachers' Thinking. International Journal of Educational Research, vol. 29, n. 3, 227-240.

Martínez, M., Sauleda, N. \& Huber, G. (2001). Metaphors as Blueprints of Thinking about Teaching and Learning. Teaching and Teacher Education, vol. 17, n. 8, 965-977.

Nikitina, L. \& Furuoka, F. (2008). A Language Teacher is Like...": Examining Malaysian Students' Perceptions of Language Teachers through Metaphor Analysis. Electronic Journal of Foreign Language Teaching, vol. 5, n. 2, 192-205.

Northcote, M. (2009). Educational Beliefs of Higher Education Teachers and Students: Implications for Teacher Education. Australian Journal of Teacher Education, vol. 34, n. 3, 69-81.

OECD. (2004). Reviews of National Policies for Education. Organisation for Economic Cooperation and Development.

Oxford, R. L., Tomlinson, S., Barcelos, A., Harrington, C., Lavine, R. Z., Saleh, A. \& Longhini, A. (1998). Clashing Metaphors about Classroom Teachers: Toward a Systematic Typology for the Language Teaching Field. System, vol. 26, n. 1, 3-50.

Pajares, M. F. (1992). Teachers' Beliefs and Educational Research: Cleaning Up a Messy Construct. Review of Educational Research, vol. 62, n. 3, 307-332.

Pragglejaz Group. (2007). MIP: A Method for Identifying Metaphorically Used Words in Discourse. Metaphor and Symbol, vol. 22, n. 1, 1-39.

Saban, A. (2006). Functions of Metaphor in Teaching and Teacher Education: A Review Essay. Teaching Education, vol. 17, n. 4, 299-315.

(2004). Prospective Classroom Teachers' Metaphorical Images of Selves and Comparing Them to Those They Have of Their Elementary and Cooperating Teachers. International Journal of Educational Development, vol. 24, n. 6, 617-635.

Kocbeker, B. N. \& Saban, A. (2007). Prospective Teachers' Conceptions of Teaching 
and Learning Revealed through Metaphor Analysis. Learning and Instruction, vol. 17, n. 2, 123-139. Soriano, C. (2011). La metáfora conceptual. En I. Ibarretxe-Antuñano y J. Valenzuela (Coords.), Lingüística cognitiva (pp. 97-121). Barcelona: Anthropos.

Tschannen-Moran M. \& Woolfolk, A. (2001). Teacher Efficacy: Capturing an Elusive Construct. Teaching and Teacher Education, vol. 17, n. 7, 783-805.

Tillema, H. (1998). Stability and Change in Student Teachers' Beliefs about Teaching. Teachers and Thinking: Theory and Practice, vol. 4, n. 2, 217-228.

Wan, W. (2011). An Examination of the Validity of Metaphor Analysis Studies: Problems with Metaphor Elicitation Techniques. Metaphor and the Social World, vol. 1, n. 2, 262-288. 